\title{
Correction to: Targeting the ileal bile salt transporter in the treatment of non-alcoholic fatty liver disease
}

Peter L. M. Jansen ${ }^{1}$

Published online: 22 April 2021

(c) Asian Pacific Association for the Study of the Liver 2021

Correction to: Hepatology International

https://doi.org/10.1007/s12072-021-10134-5

In the original publication of the article, the corresponding author name was repeated twice. The correct author group is given in this Correction.

Publisher's Note Springer Nature remains neutral with regard to jurisdictional claims in published maps and institutional affiliations.

The original article can be found online at https://doi.org/10.1007/ s12072-021-10134-5.

Peter L. M. Jansen

p.l.jansen@amsterdamumc.nl

1 Amsterdam University Medical Center, Meibergdreef 9, 1105 AZ Amsterdam, The Netherlands 